\title{
Non-linearity of creep coefficient
}

\section{Md. Rajibul Karim PhD}

Lecturer, School of Natural and Built Environments, University of South Australia, Mawson Lakes, Australia (corresponding author: rajibul.karim@unisa.edu.au) (Orcid:0000-0002-5318-3862)
Sik-Cheung Robert Lo PhD

Honorary Associate Professor, School of Engineering and Information Technology, University of New South Wales, Canberra, Australia

This study investigated the non-linear void ratio-log(time) relationship during creep (secondary compression) under a range of loading history. Four long-duration creep tests on reconstituted clay soils from two different sites were performed. Data from tests reported in the literature (six long-duration creep tests on reconstituted marine deposits and three long-duration creep tests on undisturbed soil samples) were also used in this investigation. A creep coefficient function that depends on both the stress state and extent of creep is proposed. According to the function, the creep rate slows down with its progression.

\section{Notations}

A positive constant

$C_{\alpha} \quad$ creep coefficient

$C_{\alpha m} \quad$ positive constant representing maximum value of creep coefficient in current study

$C_{\alpha \max }$ maximum value of the creep coefficient in

Karim et al. (2010)

$C_{\alpha \mathrm{t}} \quad$ tangential creep coefficient

e void ratio

$e_{\mathrm{N}} \quad$ void ratio on the normal consolidation line at unit mean normal effective stress

$k_{0} \quad$ at-rest earth pressure coefficient

$M \quad$ slope of the critical state failure line

$N \quad$ positive constant

$p \quad$ mean normal effective stress

$p_{\mathrm{L}} \quad$ 'creep-exclusive' preconsolidation pressure

$\bar{p}_{0} \quad$ 'creep-inclusive' preconsolidation pressure

$q \quad$ deviatoric stress

$t$ time

$\Delta e \quad$ change in void ratio

$\kappa \quad$ recompression index

$\lambda$ slope of normal consolidation established based on a standardised stress duration of $1 \mathrm{~d}$

\section{Introduction}

It has long been recognised that for some soils, secondary compression (SC) or creep can be a significant contributor to their time-dependent deformation. The estimation of SC or creep has been an active area of research for the past few decades (Berre and Iversen, 1972; Bjerrum, 1967; Gnanendran et al., 2006; Karim and Gnanendran, 2009; Karim et al., 2010, 2011; Mesri and Castro, 1987; Mesri and Godlewski, 1977; Mesri et al., 1981; Robinson, 2003; Yin and Graham, 1994, 1996, 1999). Two hypotheses are generally adopted for its estimation - namely, hypothesis ' $A$ ' and hypothesis ' $\mathrm{B}$ ' (Jamiolkowski et al., 1985). According to hypothesis A, SC occurs only after the end of primary consolidation (EOPC) and is caused by the same physical mechanisms responsible for volume changes during an increase in effective stress (e.g. deformation, slippage and reorientation of particles). Hypothesis B, on the other hand, assumes that creep occurs during all stages of plastic deformation and mostly due to viscous expulsion of absorbed water from 'double layers' around clay particles and viscous non-recoverable rearrangement and deformation of clay particles and their skeleton (Lo, 1960; Olson, 1998; Taylor and Merchant, 1940; Yin, 2013). According to Robinson (2003), SC can start at different points in time after load increment depending on the load magnitude and type of soil. Hypothesis A presents difficulties in modelling $\mathrm{SC}$ as a material property since EOPC is a function of drainage distance, which depends on the geometry and boundary conditions of the consolidating soil. On the other hand, hypothesis $\mathrm{B}$ allows the modelling of creep as a material property.

A number of elastic-viscoplastic (EVP) models of varying levels of complexity for simulating the SC or creep behaviour of soil have been proposed in the literature (Garlanger, 1972; Kutter and Sathialingam, 1992; Yin, 2001; Yin and Graham, 1996, 1999; Yin et al., 2002). Many of these models implicitly relate creep or SC to the creep or SC coefficient $\left(C_{\alpha}\right)$, which is defined as

1. $C_{\alpha}=\frac{\Delta e}{\log \left(t / t_{0}\right)}$

where $\Delta e$ is the change in void ratio, $e$, under a constant effective stress within the time period $t_{0}$ to $t$ after EOPC. The use of $C_{\alpha}$ as an input parameter to a predictive model implies that the $e-\log (t)$ relationship under constant effective stress is linear. Although this may be an adequate approximation for representing oedometer test data over a short period of time, say a few days, longduration test results suggest that the $e-\log (t)$ relationship may not be linear (Berre and Iversen, 1972; Leroueil et al., 1985; Mesri and Castro, 1987; Yin, 1999). Furthermore, the use of a constant $C_{\alpha}$ may produce misleading results (Yin, 1999).

To overcome this problem, Yin (1999) proposed a creep parameter function that simulates the non-linear variation of creep strain (thus $e$ ) with $\log (t)$ in oedometer tests. This function requires three input parameters: a limiting creep strain, an initial creep rate and a reference time for deducing creep time from the total test time. According to Yin (1999), this creep parameter is likely to be reliant 
on the vertical effective stress. A varying creep parameter can be inferred from this function, which, in turn, may be incorporated into EVP models (Yin, 1999). However, the use of a reference time for establishing creep time explicitly in the equation makes it difficult for more general applications. Mesri and Godlewski (1977) also presented a time-and-stress compressibility relationship, and it also uses time explicitly in their formulation and thus is difficult for more general application, as time may not uniquely correlate with the state of the soil.

Among others, Alonso et al. (2000) and Zhu et al. (2016) also proposed a non-linear creep function. Zhu et al. (2016) presented a way of estimating the non-linear variation of the creep coefficient as a function of the value of the creep coefficient at the liquid limit, current water content, current and initial bonding ratios, an initial value of an index representing the 'contribution of the soil structure to the creep coefficient' and two other parameters $m$ and $n$. A number of correlations were presented to deduce those parameters using the water content at the liquid limit and soil sensitivity. The Zhu et al. (2016) function can be useful in certain scenarios; however, there is scope for alternative functions to be developed. This paper develops a non-linear creep function based on longduration creep tests on two reconstituted clay soils and published data on reconstituted marine deposits and undisturbed soils.

In general, for a non-linear $e-\log (t)$ behaviour, $C_{\alpha}$ can be generalised to a tangential creep coefficient, $C_{\alpha \mathrm{t}}$, defined as

2. $C_{\alpha \mathrm{t}}=\frac{\mathrm{d} e}{\mathrm{~d}(\log t)}$

If $C_{\alpha \mathrm{t}}$ can be expressed as a function of soil state, it can simply replace $C_{\alpha}$ in the corresponding EVP models. This function can be used in association with most EVP models that use $C_{\alpha}$ as an input parameter. Karim et al. (2010) suggested that the $C_{\alpha \mathrm{t}}$ function should have the following desirable characteristics.

- The predicted creep is bounded.

- $C_{\alpha \mathrm{t}}$ reduces with the progression of creep.

- The influence of test pressure and loading history is captured.

- The function is not tied to any specific EVP model.

The first three characteristics are essential to ensure consistency and to avoid unreasonable computed results. Based on long-duration (more than 90d) creep tests conducted on soft clay from the Leneghans swamp embankment (located $150 \mathrm{~km}$ north of Sydney,
Australia), a non-linear $C_{\alpha \mathrm{t}}$ function that satisfies the aforementioned requirements, expressed as Equation 3, was proposed.

3. $C_{\alpha \mathrm{t}}=C_{\alpha \max } \exp \left[-N\left(\bar{p}_{0}-p_{\mathrm{L}}\right)\right]$

Here, $C_{\alpha \max }$ and $N$ are two positive constants; $\bar{p}_{0}$ is the 'creepinclusive' preconsolidation pressure; and $p_{\mathrm{L}}$ is 'creep-exclusive' preconsolidation pressure. The values of $C_{\alpha \max }$ and $N$ can easily be determined by fitting the function to oedometer creep test data. This $C_{\alpha \mathrm{t}}$ function is not linked to any particular EVP model, but is based on the Leonards and Altschaefl (1964) concept of 'quasipreconsolidation' of normally consolidated clay and the Bjerrum (1967) time line model. $C_{\alpha \mathrm{ot}}$ reduces with the progression of creep as measured by $\left(\bar{p}_{0}-p_{\mathrm{L}}\right)$. Expressions for $\bar{p}_{0}$ and $p_{\mathrm{L}}$ are presented in the Appendix.

Equation 3 performs well capturing the behaviour of the Leneghans swamp soft clay, with the best-fit parameters being $C_{\alpha \max }=0.085$ and $N=0.027$ (Karim et al., 2010). The scatter around the best-fit curve has a root-mean-square deviation (RMSD) of 0.0089 , which is about $10 \%$ of $C_{\alpha \max }$. This paper investigates the ability of Equation 3 in representing the creep behaviour of a wider range of soils. Along with creep test data on the Leneghans swamp soil, four additional long-duration creep tests on reconstituted clay soils from two different sites were performed. Data from six further long-duration creep tests on reconstituted marine deposits were collected for this investigation. As will be seen in next few sections, the soil types used in this study were very different from each other and represented a very wide range of soil types. Based on the creep test data, an alternative function is proposed that can better capture the nonlinearity of the creep coefficient on a wider range of soils.

\section{Creep test on red mud}

Oedometer creep tests were conducted on reconstituted soft clay samples collected from two sites (hereafter referred to as site 1 and site 2) located in North Queensland, Australia. These soft clays are referred to as red mud, which are, in fact, alumina tailings deposits. The soil from site 1 had a natural moisture content of $8.5 \%$ and contained $50 \%$ clay, $48 \%$ silt and about $2 \%$ fine pebbles. It had a liquid limit of $86 \%$ and a plastic limit of $46 \%$ with a plasticity index of $40 \%$. The soil from site 2 , on the other hand, contained about $43 \%$ clay, $22 \%$ silt, $23 \%$ sand and about $13 \%$ fine pebbles. It had a liquid limit of $49 \%$ with a natural moisture content of $42 \%$. The index properties of the two soils are summarised in Table 1 . Additional $\mathrm{pH}$ and electrical

Table 1. Index properties of the soils tested

\begin{tabular}{|c|c|c|c|c|c|}
\hline Soil & Natural water content: \% & Liquid limit: \% & Plastic limit: \% & Electrical conductivity: ${ }^{\mathrm{a}} \mathrm{ms} / \mathrm{S}$ & $\mathrm{pH}^{\mathrm{a}}$ \\
\hline Red mud site 1 & $80 \cdot 5$ & 86 & 46 & $6 \cdot 17$ & $9 \cdot 71$ \\
\hline Red mud site 2 & $41 \cdot 6$ & 49 & $-\mathrm{b}$ & 6.95 & $10 \cdot 86$ \\
\hline
\end{tabular}

a Tests conducted at $250 \%$ water content

${ }^{\mathrm{b}}$ Conducted test yielded no result 
conductivity tests were conducted, and the results are also reported in Table 1.

Reconstituted samples were prepared from soil slurry (prepared at $1.35 \times$ liquid limit) reconsolidated in $100 \mathrm{~mm}$ dia. (60 mm height) cylindrical moulds under $7-10 \mathrm{kPa}$ of vertical stress. The bulk densities of the samples calculated before the start of the oedometer tests were 15.5 and $18.5 \mathrm{kN} / \mathrm{m}^{3}$ for site 1 and site 2 , respectively. The sample was then trimmed to fit oedometer rings. To have bigger volume of samples, 63 and $70 \mathrm{~mm}$ dia. oedometer rings were used. Two different types of tests were conducted.

The first type was a step-loading test (load doubled in each step except for the last step, where the load was increased by $60 \%$ ) with the duration of each load step being $24 \mathrm{~h}$ unless further creep was allowed. For the test on site 1 soil, once the vertical stress reached $107 \mathrm{kPa}$, it was allowed to creep for $12 \mathrm{~d}$, and, after that, the stress was stepped to the final value of $349 \mathrm{kPa}$ with $24 \mathrm{~h}$ load steps. At the final stress, the soil was again allowed to creep for ten more days.

For site 2 soil, the load was stepped to the final value of $443 \mathrm{kPa}$ (no intermediate-creep stage) and then was allowed to creep for $20 \mathrm{~d}$. The step-loading test induced stress history in the soil before it was allowed to creep under constant effective stress.

The second test type, referred to as ramped-loading test hereafter, was conducted by ramping the load gradually (at rates of 0.5 and $0.7 \mathrm{kPa} / \mathrm{min}$ for site 1 and site 2 , respectively) to the final stress of $150 \mathrm{kPa}$ (for both sites). This essentially removed the effect of any stress history and any concerns due to sudden application of stresses. This test is not different from any step-loading test except for the fact that the load is ramped up rather than applied instantaneously. Once the soil reached the final stress, it was allowed to creep for more than 1 month. The creep data presented in the figures are from after the EOPC. The EOPC was determined using graphical methods, as no pore water pressure measurements were taken. To remove any concerns, data points from sufficient duration after the EOPC $(1.5$ EOPC to $24 \mathrm{~h}$ depending on data availability) were used.

A finite-difference technique was used for the calculation. Data points from only after the EOPC were used. In Table 2, the soil parameters for site 1 and site 2 are tabulated along with those for other soils discussed in this paper.

Table 2. Parameters needed for the calculation of $\bar{p}_{0}$ and $p_{\mathrm{L}}$

$\begin{array}{lccccc}\text { Soil } & \boldsymbol{\lambda} & \boldsymbol{\kappa} & \boldsymbol{M} & \boldsymbol{e}_{\mathbf{N}} & \boldsymbol{k}_{\mathbf{0}} \\ \text { Leneghans swamp } & 0.380 & 0.0760 & 1.113 & 3.29 & 0.53 \\ \text { Hong Kong marine deposit } & 0.219 & 0.0439 & 1.265 & 2.37 & \\ \text { Red mud site 1 } & 0.201 & 0.0400 & 1.110 & 2.74 & \\ \text { Red mud site 2 } & 0.082 & 0.0164 & 1.110 & 1.33 & \end{array}$

$k_{0}$ is the at-rest earth pressure coefficient; all other symbols are defined in the Appendix
Figure 1 presents $C_{\alpha \mathrm{t}}$ plotted against time for site 1. Data from all the tests show a pattern of $C_{\alpha \mathrm{t}}$ decreasing with the progression of creep. However, they fall in two distinct groups. To examine the effectiveness of Equation 3 in simulating these data, $C_{o t}$ values from site 1 are plotted against $\left(\bar{p}_{0}-p_{\mathrm{L}}\right)$ in Figure 2. This time, data points from tests conducted under 107 and $150 \mathrm{kPa}$ fall within close vicinity of each other although they were conducted with different stress histories. The $349 \mathrm{kPa}$ test data, on the other hand, fall away from this group. This indicates that the influence of test pressure is not adequately captured by $\left(\bar{p}_{0}-p_{\mathrm{L}}\right)$ in Equation 3. A similar observation can be made for the case of site 2 soil, which is presented in Figure 3.

\section{Creep test on Hong Kong marine deposit}

Yin (1999) presented a set of long-duration oedometer creep test results conducted on reconstituted Hong Kong marine deposits (HKMD). Tests were conducted under $10-800 \mathrm{kPa}$ first-time

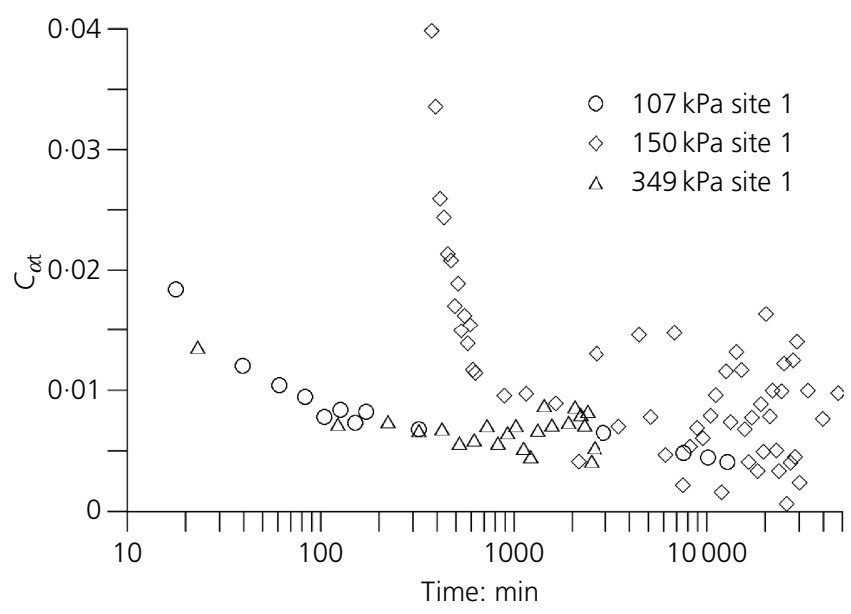

Figure 1. $C_{\alpha \mathrm{t}}$ plotted against time for the case of red mud (site 1)

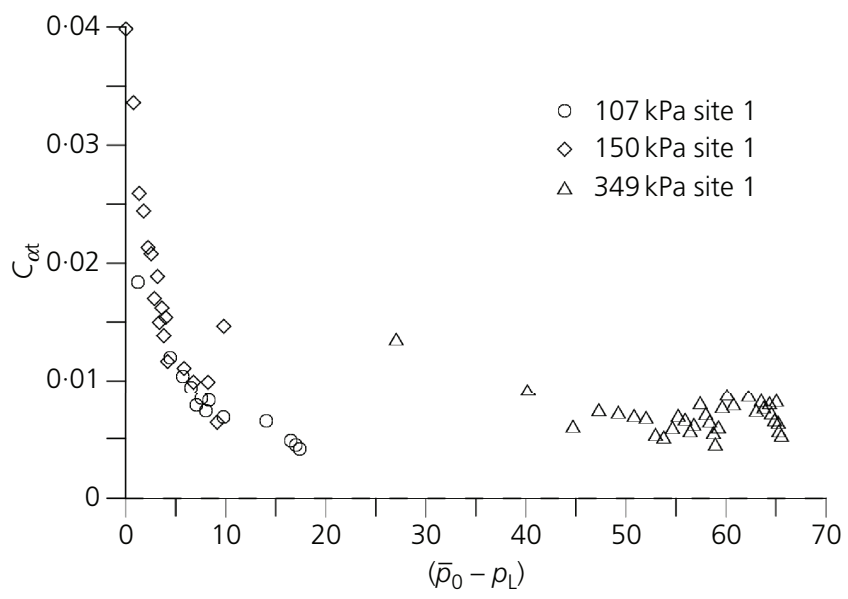

Figure 2. $C_{\alpha \mathrm{t}}$ plotted against $\left(\bar{p}_{0}-p_{\mathrm{L}}\right)$ for the case of red mud (site 1) 


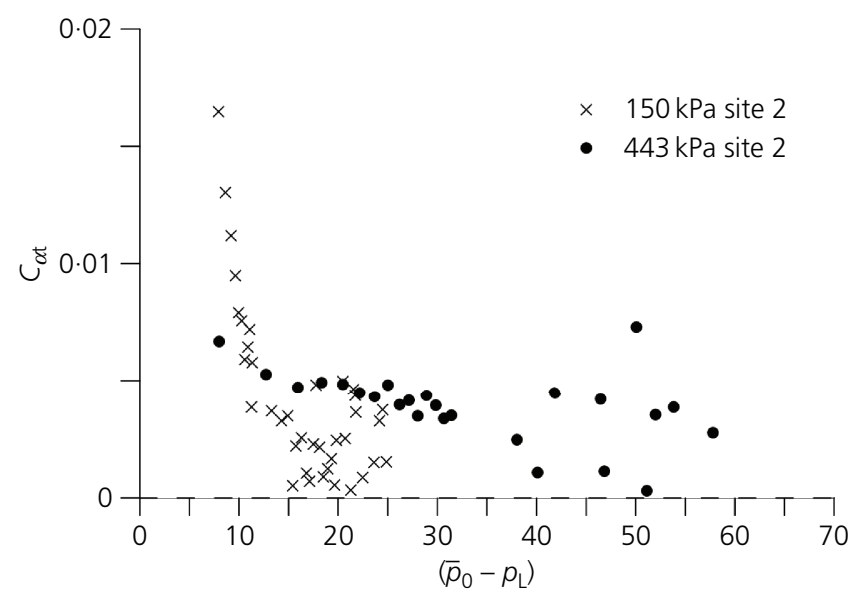

Figure 3. $C_{\alpha \mathrm{t}}$ plotted against $\left(\bar{p}_{0}-p_{\mathrm{L}}\right)$ for the case of red mud (site 2)

loading. After the stress reached $800 \mathrm{kPa}$, some of the samples were unloaded and then reloaded $(75-400 \mathrm{kPa})$. Data points from creep tests conducted under 50,100, 200 and $800 \mathrm{kPa}$ first-time loading plus the $400 \mathrm{kPa}$ reloading tests were considered for this study. The curves from the published plots were digitised so that $C_{\alpha \mathrm{t}}$ values could be calculated objectively using a finite-difference technique. Parameters used for calculating $\bar{p}_{0}$ and $p_{\mathrm{L}}$ for HKMD are presented in Table 2 .

The $C_{\alpha \mathrm{t}}$ values so deduced are plotted against time in Figure 4 . The data points are from the first-time loading and reloading test (after first-time loading to $800 \mathrm{kPa}$ and unloading to $50 \mathrm{kPa}$ ). Although individual tests show a decrease in $C_{o t}$ with time, the data points from different tests scatter all over the plotted area that is, they do not show any trend at all. In Figure 5, the same data points are plotted against $\left(\bar{p}_{0}-p_{\mathrm{L}}\right)$. This time, an overall pattern of $C_{\alpha \mathrm{t}}$ decreasing with $\left(\bar{p}_{0}-p_{\mathrm{L}}\right)$ is manifested, but the data scatter is still considerable. The data points for tests conducted at

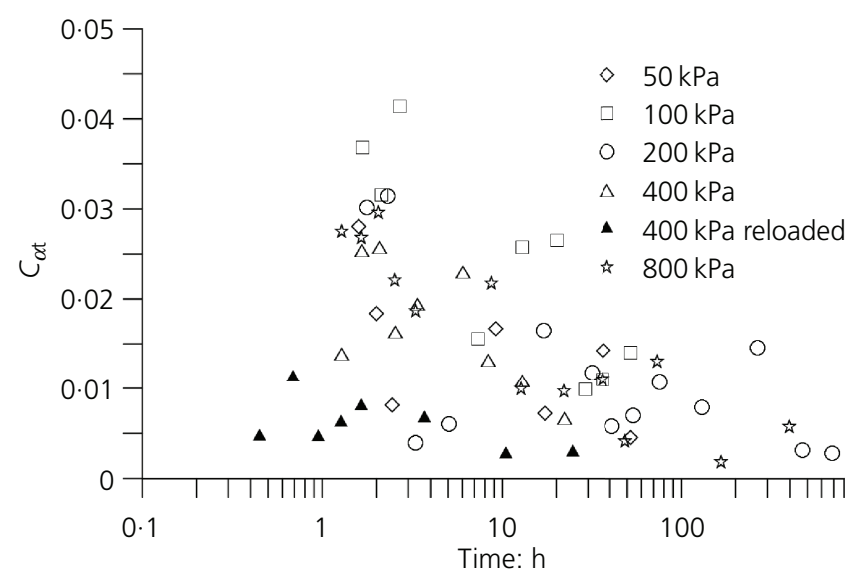

Figure 4. $C_{\alpha t}$ plotted against time for the case of HKMD

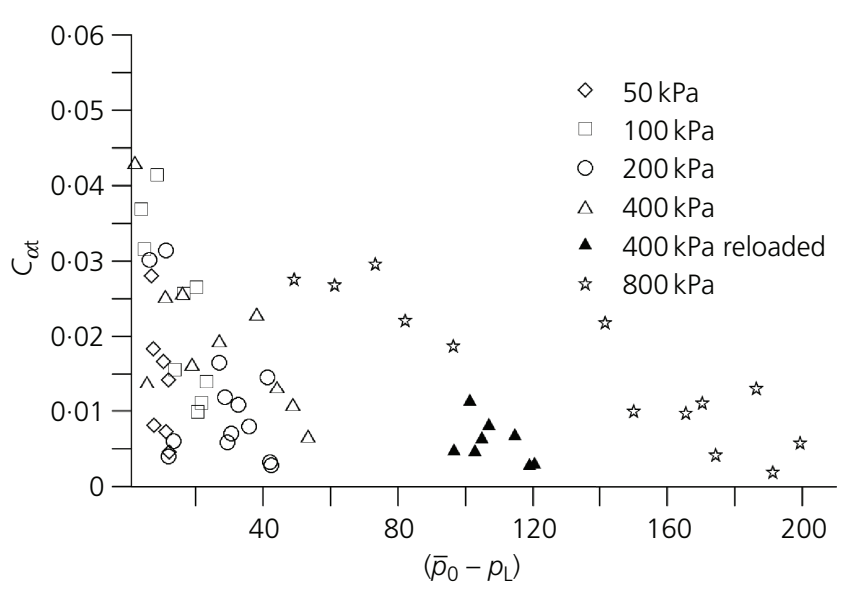

Figure 5. $C_{\alpha \mathrm{t}}$ plotted against $\left(\bar{p}_{0}-p_{\mathrm{L}}\right)$ for the case of HKMD

stress up to $400 \mathrm{kPa}$ group together and show a trend, whereas the $800 \mathrm{kPa}$ first-time loading and $400 \mathrm{kPa}$ reloading test data fall away from the group. This suggests that in this case as well, the term $\left(\bar{p}_{0}-p_{\mathrm{L}}\right)$ may not be adequately representing the progression of creep over a wider range of stresses.

\section{An alternative $\boldsymbol{C}_{\alpha \mathbf{t}}$ function}

In an attempt to remove some of the effect of higher stress on $C_{\alpha \mathrm{t}}$, the term $\left(\bar{p}_{0}-p_{\mathrm{L}}\right)$ is normalised by $p_{\mathrm{L}}$. This means that the extent of creep is represented by an alternative parameter $\left(\bar{p}_{0} / p_{\mathrm{L}}-1\right)$. The effectiveness of this alternative measure can now be examined by plotting $C_{\alpha \mathrm{t}}$ against $\bar{p}_{0} / p_{\mathrm{L}}$.

In Figure 6, $C_{\alpha \mathrm{t}}$ data for the red mud from both site 1 and site 2 are replotted against $\bar{p}_{0} / p_{\mathrm{L}}$. The data points for a given site, although conducted with different test methods and test pressures, now follow a combined trend. Although some scatter is still evident, there is no 'grouping' of the data points, and a much

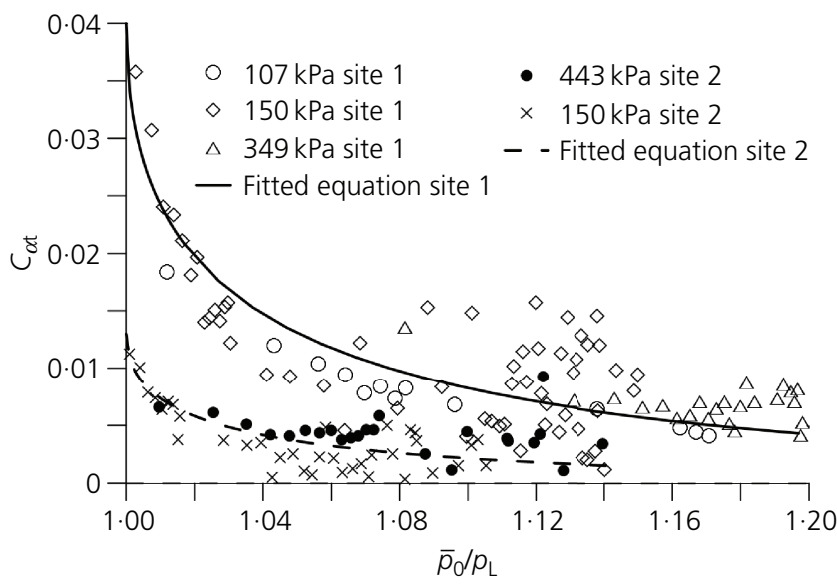

Figure 6. $C_{\alpha \mathrm{t}}$ plotted against $\bar{p}_{0} / p_{\mathrm{L}}$ for the case of red mud (site 1 and site 2) 
smoother trend of $C_{\alpha \mathrm{t}}$ decreasing with $\bar{p}_{0} / p_{\mathrm{L}}$ is observed. Data points deduced from a test under a wide range of vertical stresses come much closer to each other, and the amount of scatter observed in Figure 2 reduces significantly. These data points can now be fitted by an alternative $C_{\alpha \mathrm{t}}$ function presented as the following equation

$$
\text { 4. } C_{\alpha \mathrm{t}}=C_{\alpha m} \exp \left[-A \sqrt{\left(\frac{\bar{p}_{0}}{p_{L}}-1\right)}\right]
$$

Here, $C_{\alpha m}$ and $A$ are two positive constants. The best-fit equations are shown in the figure as a solid line for site 1 and as a dotted line for site 2 .

This equation has all the features of Equation 3 except that in measuring the extent of creep, $\left(\bar{p}_{0} / p_{\mathrm{L}}-1\right)$ replaces $\left(\bar{p}_{0}-p_{\mathrm{L}}\right)$ in order to capture adequately the dependency of $C_{\alpha \mathrm{t}}$ on stress. It is to be noted that this equation does not differentiate between the mechanisms by which the difference between the $\bar{p}_{0}$ and $p_{\mathrm{L}}$ occurs. $C_{\alpha \mathrm{t}}$ is determined by the ratio $\bar{p}_{0} / p_{\mathrm{L}}$, which could occur due to soil creep when $\bar{p}_{0}$ increases or due to unloading when $p_{\mathrm{L}}$ decreases.

Figure 7 shows the $C_{\alpha \mathrm{t}}$ values for HKMD plotted against $\bar{p}_{0}-p_{\mathrm{L}}$. Both first-time loading and reloading test data points are used. The data points, as a first approximation, may be assumed as following a single trend, although there is evident scatter around the best-fit curve. This may be caused by the inevitable error introduced in digitising from published figures plotted at small scale. The calculated RMSD for this was 0.0078 (an improvement over Equation 3, RMSD $=0.012$ ). Furthermore, there is no grouping of data points depending on stress levels.

To ensure that the alternative function is still applicable to the soft clay beneath the Leneghans swamp embankment, the $C_{\alpha \mathrm{t}}$ data presented by Karim et al. (2010) were replotted against $\bar{p}_{0} / p_{\mathrm{L}}$ in Figure 8 . This time as well, $C_{o \mathrm{t}}$ values from tests conducted under

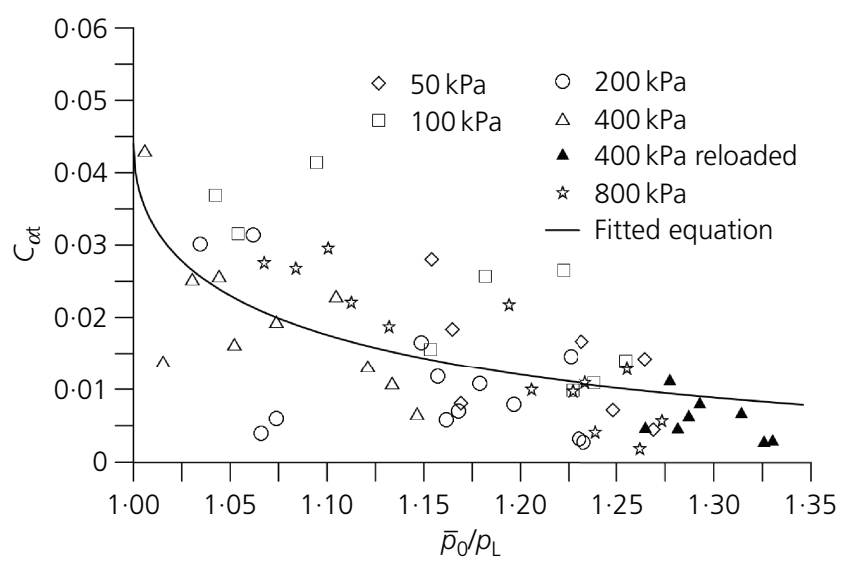

Figure 7. $C_{\alpha \mathrm{t}}$ plotted against $\bar{p}_{0} / p_{\mathrm{L}}$ for the case of HKMD

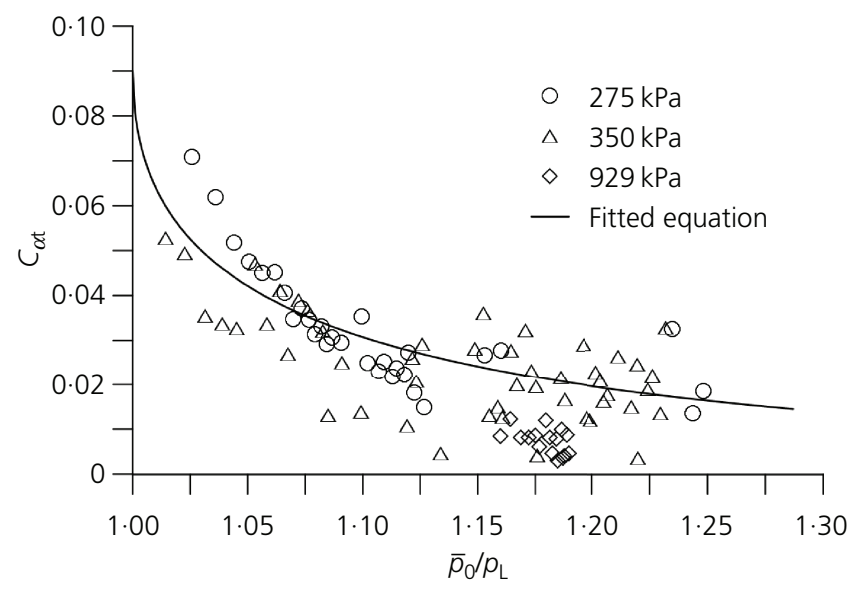

Figure 8. $C_{\alpha \mathrm{t}}$ plotted against $\bar{p}_{0} / p_{\mathrm{L}}$ for the case of Leneghans swamp

a very wide range of stresses $(275-929 \mathrm{kPa})$ can still be described by a single trend. The scatter around the best-fit curve had an RMSD of 0.0090 , which is essentially the same as that obtained using Equation 3.

\section{Determining the creep function parameters}

The creep function in Equation 3 uses four parameters - namely, $C_{\alpha m}, A, p_{\mathrm{L}}$ and $\bar{p}_{0}$. Among these, $p_{\mathrm{L}}$ and $\bar{p}_{0}$ can be calculated as shown in the Appendix using conventional modified Cam Clay parameters - that is, compression and recompression indices ( $\lambda$ and $\kappa$ ), slope of the critical state line $(M)$ and void ratio on the normal consolidation line at unit mean normal effective stress $\left(e_{\mathrm{N}}\right)$. For the estimation of $C_{\alpha m}$ and $A$, long-duration creep tests (preferably longer than 1 week) will be required. The parameters $C_{\alpha m}$ and $A$ now can be estimated by fitting the data in a plot similar to Figure 6, 7 or 8 . Creep test data from under different stresses are preferable.

\section{Limitations of the current study}

It is to be noted that no pore water pressure measurement was taken and the end of consolidation for different tests was estimated using graphical methods. The data presented on HKMD were digitised from published papers, and the process could introduce some error and was probably responsible for considerable data scatter.

\section{Conclusion}

This paper presents a unique relationship that is capable of representing the non-linear variation of the creep coefficient with progression of creep and stress state. This relationship 'measures' the extent of creep based on the concept of quasi-preconsolidation and is not tied to any specific EVP model. The proposed equation was tested against four different types of soils (i.e. reconstituted red mud from two sites in North Queensland, undisturbed soil from Leneghans swamp and reconstituted samples of HKMD). The proposed function was able to capture the non-linear 
behaviour of the creep coefficient for all these soils under a wide range of stresses and performed significantly better than the original equation proposed by Karim et al. (2010).

\section{Appendix}

As explained by Kutter and Sathialingam (1992), based on the assumption the compression and recompression lines are straight in the $e-\ln (p)$ space, $\bar{p}_{0}$ can be calculated using the following equation

5. $\bar{p}_{0}=\exp \left[\frac{e_{\mathrm{N}}-e-\kappa \ln p}{(\lambda-\kappa)}\right]$

With the assumption of an elliptical yield surface, $p_{\mathrm{L}}$ can be calculated using the following equation

6. $p_{L}=p+\frac{q^{2}}{p M^{2}}$

where $p$ is the mean normal effective stress; $q$ is the deviatoric stress; $M$ is the slope of the critical state failure line; $\lambda$ is the slope of normal consolidation established based on a standardised stress duration of $1 \mathrm{~d} ; e_{\mathrm{N}}$ is the void ratio at $p=1$ on the same normal consolidation line; and $\kappa$ is the recompression index.

\section{REFERENCES}

Alonso EE, Gens A and Lloret A (2000) Precompression design for secondary settlement reduction. Géotechnique 50(6): 645-656, https:// doi.org/10.1680/geot.2000.50.6.645.

Berre T and Iversen K (1972) Oedometer tests with different specimen heights on a clay exhibiting large secondary compression. Géotechnique 22(1): 53-70, https://doi.org/10.1680/geot.1972.22.1.53.

Bjerrum L (1967) Engineering geology of Norwegian normally consolidated marine clays as related to settlements of buildings. Géotechnique 17(2): 83-118, https://doi.org/10.1680/geot.1967.17.2.83.

Garlanger JE (1972) The consolidation of soils exhibiting creep under constant effective stress. Géotechnique 22(1): 71-78, https://doi.org/ 10.1680/geot.1972.22.1.71.

Gnanendran CT, Manivannan G and Lo SCR (2006) Influence of using a creep, rate or an elastoplastic model for predicting the behaviour of embankments on soft soils. Canadian Geotechnical Journal 43(2): 134-154, https://doi.org/10.1139/t05-090.

Jamiolkowski M, Ladd CC, Germaine CT and Lancellotta R (1985) New developments in field and laboratory testing of soils. Proceedings of the XI International Conference on Soil Mechanics and Foundation Engineering, San Francisco, CA, USA, pp. 57-153.

Karim MR and Gnanendran CT (2009) An elastic viscoplastic model that takes into account the non-linear nature of creep of soils. Proceedings of the 2nd International Conference on Long term Behaviour of Dams, Graz, Austria.

Karim MR, Gnanendran CT, Lo SCR and Mak J (2010) Predicting the longterm performance of a wide embankment on soft soil using an elasticvisco-plastic model. Canadian Geotechnical Journal 47(2): 244-257, https://doi.org/10.1139/T09-087.

Karim MR, Manivannan G, Gnanendran CT and Lo SCR (2011) Predicting the long-term performance of a geogrid-reinforced embankment on soft soil using two-dimensional finite element analysis. Canadian Geotechnical Journal 48(5): 741-753, https://doi.org/10.1139/t10-104.
Kutter BL and Sathialingam N (1992) Elastic-viscoplastic modelling of the rate-dependent behaviour of clays. Géotechnique 42(3): 427-441, https://doi.org/10.1680/geot.1992.42.3.427.

Leonards GA and Altschaefl AG (1964) Compressibility of clays. Journal of the American Society of Civil Engineers 90(5): 133-156.

Leroueil S, Kabbaj M, Tavenas F and Bouchard R (1985) Stress-strain-strain rate relation for the compressibility of sensitive natural clays. Géotechnique 35(2): 159-180, https://doi.org/10.1680/geot.1985.35.2.159.

Lo KY (1960) Secondary compression of clays. Journal of the Soil Mechanics and Foundation Division 87(4): 133-136.

Mesri G and Castro A (1987) $C_{\alpha} / C_{c}$ concept and $K_{0}$ during secondary compression. Journal of Geotechnical Engineering 113(3): 130-247, https://doi.org/10.1061/(ASCE)0733-9410(1987)113:3(230).

Mesri G and Godlewski PM (1977) Time and stress compressibility interrelationship. Journal of the Geotechnical Engineering Division 103(5): 417-430.

Mesri G, Febres-Cordero E, Shields DR and Castro A (1981) Shear stress-strain-time behaviour of clays. Géotechnique 31(4): 537-552, https://doi.org/10.1680/geot.1981.31.4.537.

Olson RE (1998) Settlement of embankments on soft clays. Journal of Geotechnical and Geoenvironmental Engineering 124(4): 278-288, https://doi.org/10.1061/(ASCE)1090-0241(1998)124:8(659).

Robinson RG (2003) A study on the beginning of secondary compression of soils. Journal of Testing and Evaluation 31(5): 388-396, https://doi. org/10.1520/JTE12362J.

Taylor DW and Merchant W (1940) A theory of clay consolidation accounting for secondary compression. Journal of Mathematics and Physics 19(1-4): 167-185, https://doi.org/10.1002/sapm1940191167.

Yin JH (1999) Non-linear creep of soils in odeometer tests. Géotechnique 49(5): 699-707, https://doi.org/10.1680/geot.1999.49.5.699.

Yin JH (2001) A refined elastic visco-plastic model for clayey soils. Geotechnical Engineering Journal 32(1): 23-31.

Yin JH (2013) Review of elastic visco-plastic modeling of the time-dependent stress-strain behavior of soils and its extensions and applications. In Constitutive Modeling of Geomaterials (Yang Q, Zhang JM, Zheng H and Yao Y (eds)). Springer, Berlin, Germany, pp. 149-157.

Yin JH and Graham J (1994) Equivalent times and one dimensional elastic visco-plastic modelling of time dependent stress-strain behaviour of clays. Canadian Geotechnical Journal 31(1): 42-52, https://doi.org/ 10.1139/t94-005.

Yin JH and Graham J (1996) Elastic visco-plastic modelling of onedimensional consolidation. Géotechnique 46(3): 515-527, https://doi. org/10.1680/geot.1996.46.3.515.

Yin JH and Graham J (1999) Elastic viscoplastic modeling of timedependent stress-strain behaviour of soils. Canadian Geotechnical Journal 36(4): 736-745, https://doi.org/10.1139/t99-042.

Yin JH, Zhu JG and Graham J (2002) A new elastic viscoplastic model for time dependent behaviour of normally and overconsolidated clays: theory and verification. Canadian Geotechnical Journal 39(1): 157-173, https://doi.org/10.1139/t01-074.

Zhu QY, Yin ZY, Hicher PY and Shen SL (2016) Nonlinearity of onedimensional creep characteristics of soft clays. Acta Geotechnica 11(4): 887-900, https://doi.org/10.1007/s12205-016-1026-z.

\section{How can you contribute?}

To discuss this paper, please submit up to 500 words to the editor at journals@ice.org.uk. Your contribution will be forwarded to the author(s) for a reply and, if considered appropriate by the editorial board, it will be published as a discussion in a future issue of the journal. 